\title{
Microparticles in Table Salt: Levels and Chemical Composition of the Smallest Dimensional Fraction
}

\author{
Monia Renzi *(D), Eleonora Grazioli, Eleonora Bertacchini and Andrea Blašković \\ Bioscience Research Center, Via Aurelia Vecchia, 32, 58015 Orbetello (GR), Italy \\ * Correspondence: monia.renzi@bsrc.it; Tel.: +39-0564-1828033
}

Received: 3 July 2019; Accepted: 2 September 2019; Published: 6 September 2019

check for updates

\begin{abstract}
This study evaluates the chemical composition of microplastic materials (MPs) and non-synthetic particles in different table salts of marine origin by the $\mu \mathrm{FT}-\mathrm{IR}$ technique. This research focuses on the microparticles fraction within 10-150 $\mu \mathrm{m}$ of size. Eleven commercial trademarks coming from Italy $(\mathrm{IT}=6)$ and Croatia $(\mathrm{CRO}=5)$ were grouped in two different cost ranges, cheap $(n=5)$ and expensive $(n=6)$ and were analysed in replicates $(n=3)$. Levels and chemical composition of microparticles measured in commercial products were correlated on a statistical basis to some factors of variability of potential scientific interest (geographical origin of marine salt, cost of commercial products, etc.). Results of analyses performed on the tested size fraction of microparticles $(10-150 \mu \mathrm{m}$ ) evidence that: (i) levels of MPs are within 0.17-0.32 items/g (IT) and 0.07-0.20 items/g (CRO); (ii) non-synthetic particles detected are mostly made by fibres made of cellulose acetate; (iii) Nations show a different chemical composition of MPs recovered in analysed trademarks (PET and PVC from Italy; PA, PP, and nylon from Croatia); (iv) the annual amount ingested by humans from marine salt consumption ranges between 131.4-372.3 items/y (CRO) and 306.6-580.35 items/y (IT) considering a dose of $5 \mathrm{~g}$ of salt per day; (v) statistics performed on factors of interest evidenced that the geographical origin of marine salt do not affect neither levels nor chemical composition of MPs in tested trademarks; while slight correlations are recorded with non-synthetic particles. Further studies are needed to better explore on statistical basis if both levels and chemical composition of MPs in table salts of marine origin can be used or not as good indicators of marine pollution.
\end{abstract}

Keywords: plastic litter; Marine Strategy Framework Directive; D10; $\mu$ FT-IR analysis; $10-150 \mu \mathrm{m}$; chemical composition of microplastic

\section{Introduction}

In 2015, the annual global plastic production worldwide was estimated to be 322 million tonnes [1]. Eriksen et al. [2] reported that over 5 trillion of plastic debris is to date afloat at sea. In 1997, Charles Moore discovered the Great Pacific Garbage Patch, but mid-ocean gyres are only the tip of the iceberg of plastic pollution. In fact, as reported by literature [3], the plastic fraction that actually floats on the oceans represents only $1 \%$ of the total amount of plastic produced globally to date and it is expected that the levels of floating plastic will grow over time as a result of huge inputs from in-land deposits. Furthermore, primary larger microplastics fragments that are most commonly found in industrial, domestic cleaning products and synthetic textiles will originate over time secondary microplastics, by the fragmentation via weathering, ultraviolet degradation, or biodegradation [1]. Concerning dimension, microplastics are defined by GESAMP [4] as plastic pieces less than $5 \mathrm{~mm}$ in size; no lower limits are defined. Lusher et al. [5] reported $0.1 \mu \mathrm{m}$ to be the upper limit for nanoparticles. Recently Frias and Nash [6] defined microplastics as "any synthetic solid particle or polymeric matrix, with regular or irregular shape and with size ranging from $1 \mu \mathrm{m}$ to $5 \mathrm{~mm}$, of either primary or secondary manufacturing origin, which are insoluble in water". To date microplastics have been detected in water $[7,8]$, 
and sediments [9] coming from different environments worldwide: sea surface and water column [10], lakes and rivers [4,11], coastal areas [12], harbours [13], marine protected areas [14], deep oceans [15], polar ecosystems [16], and coral reefs [17].

The presence of microplastic at different levels of the aquatic trophic web was documented by the literature [18]; D'Alessandro et al. [19] reported relationships among the plastic litter, chemical pollutants and observed benthic biodiversity. Microplastic is recorded in edible seafood and mariculture products $[20,21]$ such as pelagic fish species [22], benthic species [15,23], bivalves [24-26], holothurians [27], and marine mammals [28] as wider documented by the recent literature [29], and citations therein. However, at this time, there are no specific regulations in Europe [30]. Microplastics are present in different marine made human foodstuffs, and Kosuth et al. [31] estimated that the average person ingests over 5800 particles of synthetic debris only from tap water, salt, and beer consumption. In spite of that, data on the destination of microplastics in the human body following their ingestion are lacking and no evidence is reported concerning the health risks associated [29]. Lusher et al. [5], on the basis of a large scientific review, reported that it is very likely that microplastics $>150 \mu \mathrm{m}$ of size are not absorbed by mammals; while they supposed that lower size could interact with mammals following different processes: absorption in lymph $(101-150 \mu \mathrm{m})$, in portal vein $(100 \mu \mathrm{m})$, access into organs $(<20 \mu \mathrm{m})$, and translocation from blood to brain and overcoming of the placental barrier $(<0.1 \mu \mathrm{m})$. The evaluation of risks associated with human health by the ingestion of microplastics $<150 \mu \mathrm{m}$ size represents the new frontier of medical researches [32]. Marine foodstuffs but, also, other human foods coming from the sea such as canned fishes [33] and marine salts [31,34-37] are affected by microplastics. Different salts types are commercialized worldwide. As reported by Iñiguez et al. [35], different processes are used to produce salt: mining (rock salt), water evaporation (lake and sea salt), and wells in non-coastal zones (river and well salts). Salts from marine origin were tested by recent researches and they resulted polluted by microplastics. Levels reported by the literature ranged within 1-806 items/kg (number of particles per kg of salt) [31,36]. Kim et al. [38] suggested the occurrence of a strong relationship among pollution of marine water and pollution observed in derived table salt. In the same study, a wide range of microplastic levels $0-1674$ items $/ \mathrm{kg}$ (one outlier of 13,629 items $/ \mathrm{kg}$ ) was reported. Kosuth et al. [31] reported over than $99 \%$ of extracted particles in salts were fibres. Renzi and Blašković [37] confirmed this data for Italian and Croatian salts. On the contrary, Karami et al. [36], reported fragments as dominant $(63.8 \%)$ followed by fibres $(25.6 \%)$, and films $(10.6 \%)$. In the same study, $171-515 \mu \mathrm{m}$ of particle size (min-max: $160-980 \mu \mathrm{m}$ ) was the principal range detected; almost all of the tested brands had 1-10 items/kg within this size range. Recent research performed on 25 unrefined marine salt trademarks worldwide evidenced that sea salt can be considered a good indicator of the magnitude of microplastic pollution in the marine environment [38]. In fact, they observed that levels positively correlated with both plastic inputs from rivers $(\mathrm{r}=0.57 ; p=0.003)$ and pollution levels in seawaters $(\mathrm{r}=0.68 ; p=0.021)$ near the production area of table salt. Recent research performed by Renzi and Blašković [37] on Italian and Croatian marine table salts evidenced that marine litter content (particles $>500 \mu \mathrm{m}$ ) could be related to the final cost of the commercial product suggesting the idea that the production process could somehow affect pollution by the marine litter of the table salt. In spite of that, neither the chemical composition nor levels of the size fraction 10-150 $\mu \mathrm{m}$ were assessed by the authors [37]. Furthermore, they specified that further studies could be useful to clarify such important aspects not yet addressed.

The aim of our study is to determine levels and chemical composition by $\mu$ FT-IR technique of the microparticles fraction lower than $150 \mu \mathrm{m}$ of size in different trademarks of Italian and Croatian table salts of marine origin. The dimensional cut-off to max $150 \mu \mathrm{m}$ was performed according to Lusher et al. [5] which reported that, on the basis of a large literature review performed and at the best of the actual scientific knowledge, it is very likely that microplastics $>150 \mu \mathrm{m}$ are not absorbed. We focused on the same trademarks previously analysed by Renzi and Blašković [37] to correlate the obtained results to the previous ones. On microparticles detected, levels and chemical composition recorded are statistically analysed to determine relationships with other factors of specific interest 
and to highlight possible effects of both the production process and the geographical origin on the observed assessment.

\section{Materials and Methods}

\subsection{Salt Samples of Marine Origin}

Eleven commercial trademarks coming from Italy $(\mathrm{IT}=6)$ and Croatia $(\mathrm{CRO}=5)$ were selected from two different cost ranges: cheap $(n=5)$ and expensive $(n=6)$; each trademark was analysed in replicates $(n=3)$. The same commercial lots that were analysed by Renzi and Blašković [37] were tested in this study to allow comparisons with previously determined parameters of specific interest for this new research (i.e., TSS, MPs levels). In fact, on these commercial trademarks, data on the total amount of marine litter, total impurities, shape, size, and colour of microplastics were known and obtained following criteria reported by the literature [39-41]. Low cost (LC) Italian trademarks ranged within $0.35-0.37$ Euros, while high cost (HC) ranged within 0.45-0.50 Euros.

\subsection{Laboratory Analyses}

In this study, Italian (6 IT; 3 HC and 3 LC) and Croatian (5 CRO; 3 HC and 2 LC) trademarks of iodate fine table salts of marine origin were tested. Representative aliquots of each tested trademark were obtained by collecting four subsamples of $10 \mathrm{~g}$ from the whole salt amount in the original commercial envelope; subsamples were merged and extracted as a single sample. This procedure was repeated to obtain three different analytical replicates per each representative aliquot $(n=3)$. Representative aliquots collected were weighed and completely dissolved in distilled water MQ $(360 \mathrm{~g} / \mathrm{L})$ in a Becker glass following the sample treatment reported in the literature [37]. Original commercial envelopes were made by carton for all Italian trademarks and for HC4 (Croatian); other $\mathrm{CRO}$ trademarks were packed in plastic. Dissolved salt samples were filtered by $50 \mathrm{~mL}$ Luer-lock glass syringe on Anodisc ${ }^{\circledR}$ (aluminium oxide membrane; $0.2 \mu \mathrm{m}$ pore dimension, $\mathrm{pH}$ and temperature within the membranes' acceptable range) using a $13 \mathrm{~mm}$ PTFE syringe filter holder. Wet Anodisc ${ }^{\circledR}$ filters (Whatman, lot n. A21184266) were collected in a decontaminated glass Petri dish, closed and dried in oven at $35^{\circ} \mathrm{C}$ till complete evaporation of water. Equipment for samples pre-treatments was purchased by Sartorius and Thermo Scientific and pre-rinsed to remove contaminations. In this study, chemical composition of microparticles within 10-150 $\mu \mathrm{m}$ of size was determined by the microscopy associated to Fourier Transform Infrared Spectroscopy technique (Figure 1a-c). Nicolet ${ }^{\mathrm{TM}} \mathrm{iN}^{\mathrm{TM}} 10 \mathrm{MX}$ ( $\mu$ FT-IR, Thermo Fisher Scientific) was equipped with liquid nitrogen cooled MCT-A operating within the spectral range 7800-650 $\mathrm{cm}^{-1}$ and with OMNIC ${ }^{\mathrm{TM}}$ Picta $^{\mathrm{TM}}$ (Thermo Scientific, Waltham, MA, USA) users' interface. Membranes were, first of all, fully analysed by the Wizard-operating mode by transmission. Maximum dimensions were determined measuring width for fragments and length for fibres. To perform length measurements, a mosaic is analyzed and several points are chosen with the Wizard section of OMNIC ${ }^{\mathrm{TM}}$ Picta $^{\mathrm{TM}}$ software and the length of every particle were collected by the imaging section of the software. In case of complex particles, we preferred the "tip and shoot" operating mode to improve focusing resolution. Particles thinner than $35 \mu \mathrm{m}$ were processed by trasmittance mode (spectral range $7800-650 \mathrm{~cm}^{-1}$ ). Instead particles with a thickness $>35 \mu \mathrm{m}$, or particles with uncertainty associations, were identified by mid-infrared spectroscopy in ATR (Attenuated Total Reflection) using a germanium crystal (spectral range 3000- $1300 \mathrm{~cm}^{-1}$ ). Double peak system ranging between $2350-2300 \mathrm{~cm}^{-1}$ was corrected using the "atmospheric correction" mode available in the $\mathrm{OMNIC}^{\mathrm{TM}}$ Picta $^{\mathrm{TM}}$ software. Chemical identification was performed using a specific section of the $\mathrm{OMNIC}^{\mathrm{TM}}$ Picta $^{\mathrm{TM}}$ and $\mathrm{OMNIC}^{\mathrm{TM}}$ Specta ${ }^{\mathrm{TM}}$ software. On each field several points per particle were selected, and each collected spectrum were processed and identified with specific reference libraries available in the OMNIC ${ }^{\mathrm{TM}}$ Picta $^{\mathrm{TM}}$ software. The threshold for IR spectra back-recognition was fixed over $65 \%$ of match. Limit of detection was $10 \mu \mathrm{m}$ of maximum size. Concerning microplastic amounts, LOQ was 0.02 items/g. 

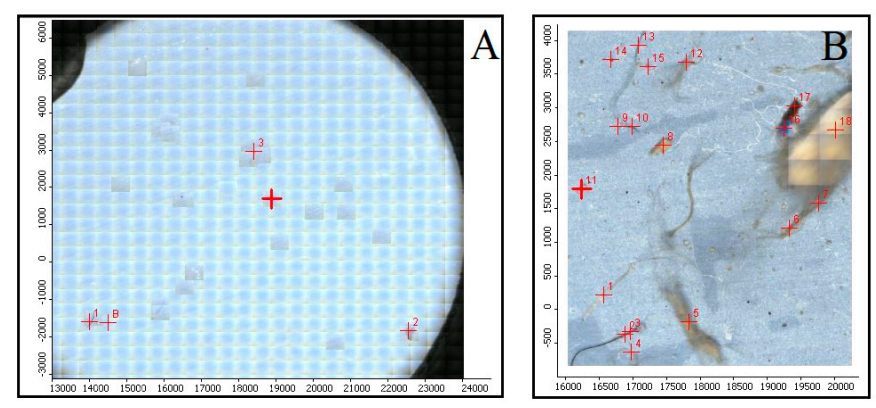

(a)

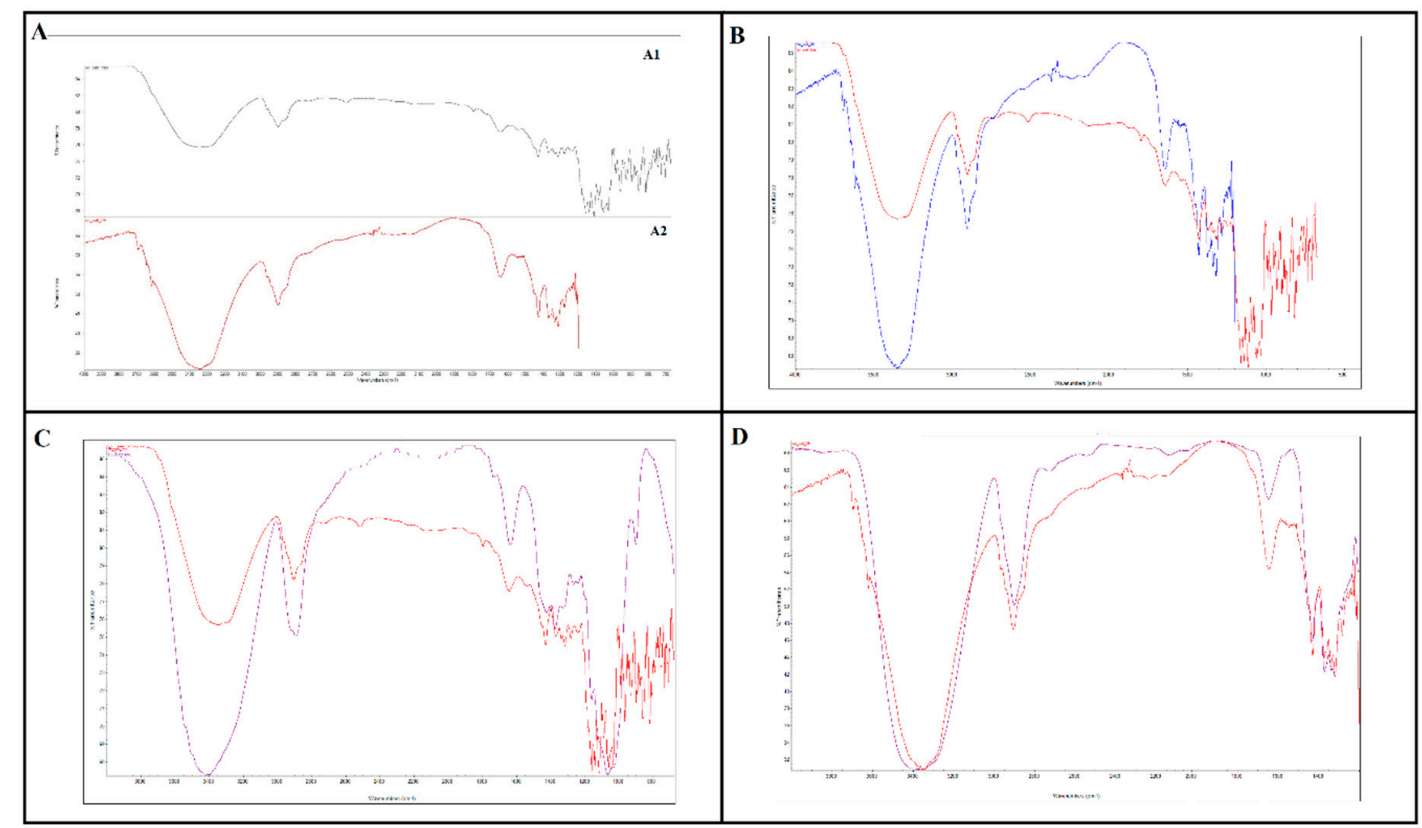

(b)

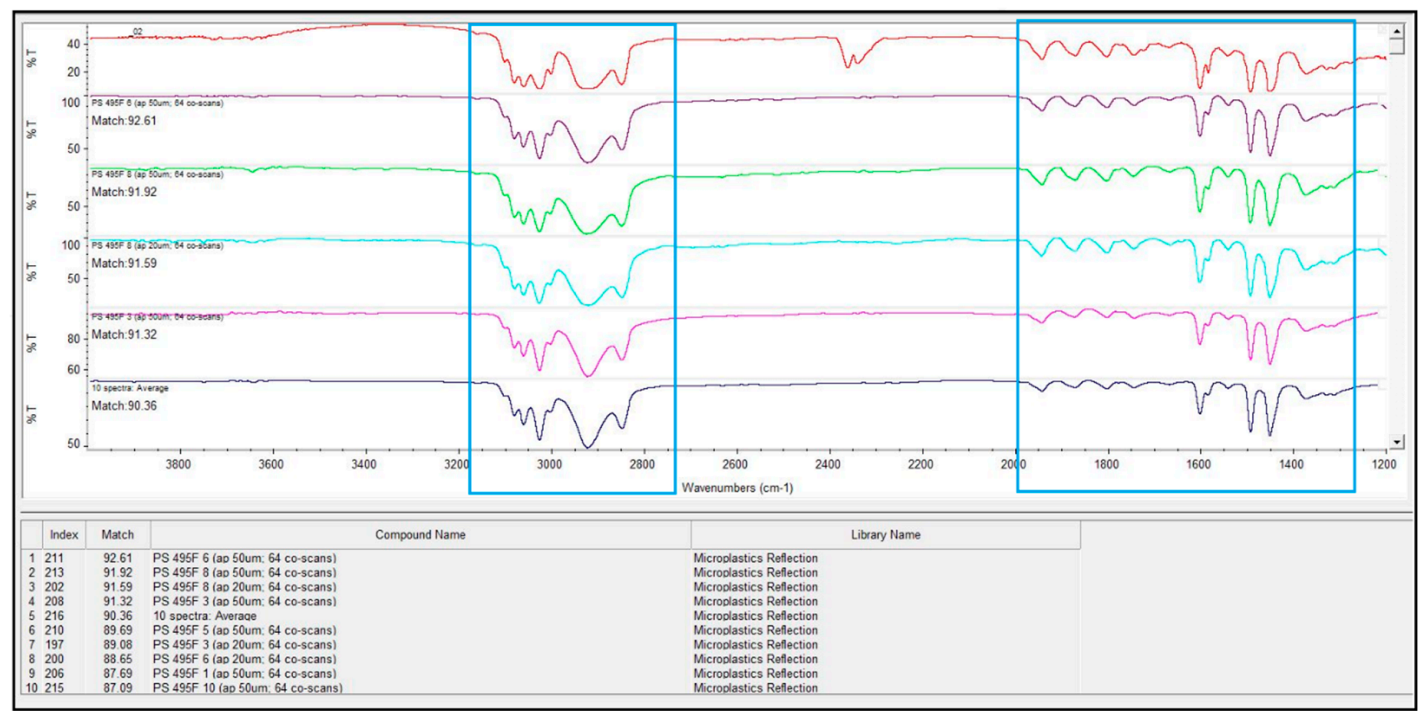

(c)

Figure 1. (a) Different magnification obtained with $\mu \mathrm{FT}-\mathrm{IR}$ using imaging section of $\mathrm{OMNIC}^{\mathrm{TM}}$ Picta $^{\mathrm{TM}}$ software. (A): mosaic acquisition. (B): target positioning. (C): maximum magnification, framed particle. 
(b) Examples of double identification with $\mu$ FT-IR transmittance and ATR mode. (A): spectrum: A1_spectrum acquired with transmittance mode named: XXX_tras, A2_spectrum acquired with ATR mode named XXX_09. (B): overlay of acquired spectrum with OMNIC ${ }^{\mathrm{TM}}$ Specta $^{\mathrm{TM}}$ software. (C): analysis of spectrum A1 with OMNIC ${ }^{\mathrm{TM}}$ Picta $^{\mathrm{TM}}$ software, the match is $68 \%$ with cellophane, although the percentage of the match was acceptable it was preferred to investigate further as the background noise was high despite the correction made by software. (D): comparing spectrum acquired with mid-infrared spectroscopy in ATR allowed to determine at $88 \%$ match that particle was cellulose and not a plastic material, avoiding an overestimation of the data. Specific reference libraries are used for spectrum analysis in analysis section of the OMNIC ${ }^{\mathrm{TM}}$ Picta $^{\mathrm{TM}}$ software. Double peak system ranging between 2350 and $2300 \mathrm{~cm}^{-1}$ each spectrum was corrected using the "atmospheric correction" mode available in the OMNIC ${ }^{\mathrm{TM}}$ Picta $^{\mathrm{TM}}$ software. (c) $\mu$ FT-IR analysis: third spectrum of sample (red line) acquired with spectroscopy in ATR using Microplastic reflection library, (before atmospheric correction). The match obtained for polystyrene is $92.61 \%$.

\subsection{Quality Assurance \& Quality Control}

According to literature [42], some rules to reduce cross-contamination of samples were followed. In particular, plastic materials were avoided and substituted with glassware or metals; during sampling handlings synthetic textiles were not allowed and operators wear cotton clothes and $100 \%$ cotton lab coat; laboratory surfaces were cleaned with $70 \%$ ethanol and paper towels while equipment was accurately rinsed as reported by literature [14,43]. Consumables were used directly from packaging and all working solutions were pre-filtered and stored in glass bottles before the use. Samples were kept covered as much as possible, treatments were performed in a dedicated laboratory room under vertical air laminar flow fume hood equipped with HEPA filtration units to reduce plastics airborne. Experimental blanks were tested during extractions, filtration, and evaporation processes. Experimental blanks $(n=3)$ were prepared as follows: an equivalent volume of deionized water was mixed in glass Becker for a long-time interval like that of the salt samples. After that, blanks were filtered on Anodisc ${ }^{\circledR}$, dried in oven, and tested by $\mu$ FT-IR to check for microplastics. Another set of wet Anodisc ${ }^{\circledR}$ were kept overnight in an open Petri dish, dried in oven and analysed to test airborne contamination. No microplastics were recorded in blanks; we recorded on average $1.3 \pm 1.5$ tan fibres of cotton. LOQ was 2.8 items $/ \mathrm{kg}$ of salt.

\subsection{Statistical Analyses}

Results on microparticle fraction 10-150 $\mu \mathrm{m}$ of size were grouped according to chemical nature of particles. In particular, microplastics (MPs) and other materials than plastics (non-synthetic; i.e., cellulose, quartz, cellulose acetate, etc.); these two different databases were tested separately. Collected data on each salt sample was grouped, also, according to their geographical origin (Nation, geographical origin of salt, sea of origin), and market costs (high cost, HC; low cost, LC) to evaluate if both levels and chemical composition of microparticles within 10-150 $\mu \mathrm{m}$ could be affected by the geographical origin of production but also by some other factors of specific interest (costs, total impurities, etc.). Furthermore, before packaging, the crystallized salt is subjected to many physical processes that could alter microplastic content in the final commercial product (Iñiguez et al., 2017), for this reason, cost was consider a possible factor of specific interest. Univariate analysis was performed with GraphPad Prism v.5.0 (GraphPad Software, San Diego, CA, USA, www.graphpad.com) while multivariate analysis was performed by Primer v6.0 (Primer-E Ltd., Plymouth Marine Laboratory, Plymouth, UK) routines according to methods reported by Clarke and Warwick [44]. Raw data on mean items/g collected per each chemical type of microparticles recorded in tested salt samples were pre-treated by square root and successively normalized before multivariate analysis. Principal Component Analysis (PCA) was performed on loadings values to evaluate similarities according chemical composition of detected particles, eigenvectors associated to PCA were also reported. Non-Metric Multidimensional Scaling (nm-MDS) was performed on Euclidean matrix of distance calculated on pre-treated by weighted 
(square root) and normalized data. ANOSIM tests (one-way) were performed in order to highlight effects due to specific factors of interest (i.e., cost, Region of salt origin). Further results obtained by literature (Table 1) were also associated to results obtained by this study and tested as factors of interest (i.e., TSS, total MPs levels).

Table 1. Factors of specific interest tested on statistical basis. Total suspended solids (TSS) are reported as $\mu \mathrm{g} / \mathrm{g}$ of salt and MPs are reported as average items/g of salt. ${ }^{*}$ Reported data are extracted by the literature (Renzi and Blašković, 2018).

\begin{tabular}{cccccc}
\hline Tested Trademark & Nation & Sea of Origin & Cost & TSS * & MPs * \\
\hline IT_HC1 & ITA & Northern-Adriatic & HC & 85 & 1.6 \\
IT_HC2 & ITA & Northern-Adriatic & HC & 172 & 5.7 \\
IT_HC3 & ITA & Northern-Adriatic & HC & 122 & 3.5 \\
CRO_HC4 & CRO & Northern-Adriatic & HC & 195 & 14.5 \\
CRO_HC5 & CRO & Northern-Adriatic & HC & 105 & 17.9 \\
CRO_HC6 & CRO & Adriatic & HC & 165 & 19.0 \\
IT_LC1 & ITA & Southern-Adriatic & LC & 128 & 8.2 \\
IT_LC2 & ITA & Sicilian Sea & LC & 220 & 7.6 \\
IT_LC3 & ITA & Northern-Adriatic & LC & 152 & 6.0 \\
CRO_LC4 & CRO & Northern-Adriatic & LC & 430 & 19.8 \\
CRO_LC5 & CRO & Adriatic & LC & 270 & 13.5 \\
\hline
\end{tabular}

\section{Results}

In Table 2, results related to MPs and non-synthetic particles within 10-150 $\mu \mathrm{m}$ of size are reported as mean number of particles per $\mathrm{g}$ of salt (items/g; standard deviation, SD). Data are grouped according to both costs and Nation of production. PET, PVC, PE, PS, PA, PP, and nylon were frequently detected; while PC resin, PBMA, PU, IBVE, and viscose were detected only occasionally and are not included in Table 2. Mean total MPs for Italian trademarks are $0.17 \mathrm{items} / \mathrm{g}(\mathrm{HC})$ and 0.32 items $/ \mathrm{g}$ (LC) while mean for Croatian trademarks are comparable to Italian for HC $(0.20 \mathrm{items} / \mathrm{g})$ but lower for LC $(0.07 \mathrm{items} / \mathrm{g})$. PET and PVC in Italian salts are higher than other particles both in LC and HC trademarks. Croatian salts evidenced higher levels of PA, PP and nylon and lower levels of PET and PVC compared to Italian ones. In Table 2, levels recorded for non-synthetic particles are, also, reported.

Table 2. MPs and non-synthetic particles (total average amount and chemical composition) levels. Results are reported grouping data by Nation and cost of the commercial product. Results on microparticles within 10-150 $\mu \mathrm{m}$ of size are reported as mean number of particles per $\mathrm{g}$ of salt (items/g; standard deviation, $\mathrm{SD}$ ). Notes: $\mathrm{HC}=$ high cost; $\mathrm{LC}=$ low cost; $\mathrm{LOQ}=$ limit of quantification.

\begin{tabular}{|c|c|c|c|c|c|c|c|c|}
\hline & \multicolumn{4}{|c|}{ Italian Salts } & \multicolumn{4}{|c|}{ Croatian Salts } \\
\hline & HC Mean & $S D$ & LC Mean & $S D$ & HC Mean & $S D$ & LC Mean & $S D$ \\
\hline PET & 0.07 & 0.03 & 0.09 & 0.03 & $<\mathrm{LOQ}$ & $N C$ & 0.04 & 0.04 \\
\hline PVC & 0.07 & 0.03 & 0.16 & 0.13 & 0.06 & 0.09 & 0.01 & $N C$ \\
\hline $\mathrm{PE}$ & $<\mathrm{LOQ}$ & $N C$ & 0.02 & 0.03 & $<\mathrm{LOQ}$ & $N C$ & $<\mathrm{LOQ}$ & $N C$ \\
\hline PS & 0.04 & 0.06 & $<$ LOQ & $N C$ & $<\mathrm{LOQ}$ & $N C$ & $<\mathrm{LOQ}$ & $N C$ \\
\hline PA & $<\mathrm{LOQ}$ & $N C$ & 0.04 & 0.03 & 0.05 & 0.05 & 0.03 & 0.04 \\
\hline PP & $<\mathrm{LOQ}$ & $N C$ & $<\mathrm{LOQ}$ & $N C$ & 0.05 & 0.05 & $<\mathrm{LOQ}$ & $N C$ \\
\hline Nylon & $<$ LOQ & $N C$ & 0.02 & 0.03 & 0.04 & 0.06 & $<$ LOQ & $N C$ \\
\hline MPs & 0.17 & & 0.32 & & 0.20 & & 0.07 & \\
\hline Cellulose & 0.28 & 0.29 & 0.12 & 0.08 & 0.18 & 0.11 & 0.21 & $N C$ \\
\hline Cotton & 0.12 & 0.11 & 0.14 & 0.08 & 0.16 & 0.11 & 0.29 & 0.04 \\
\hline CA & 0.05 & $N C$ & 0.09 & 0.11 & 0.14 & 0.12 & 0.21 & 0.07 \\
\hline $\mathrm{CS}$ & 0.02 & 0.03 & 0.04 & 0.03 & $<\mathrm{LOQ}$ & $N C$ & $<\mathrm{LOQ}$ & $N C$ \\
\hline $\mathrm{CMC}$ & $<$ LOQ & $N C$ & $<\mathrm{LOQ}$ & $N C$ & $<\mathrm{LOQ}$ & $N C$ & 0.03 & 0.04 \\
\hline non-synthetic particles & 0.48 & & 0.39 & & 0.48 & & 0.74 & \\
\hline
\end{tabular}


Concerning non-synthetic particles, for Italian trademarks mean is 0.48 items $/ \mathrm{g}(\mathrm{HC})$ and 0.39 items/g (LC); while for Croatian trademarks mean is similar to Italian for HC (0.48 items/g) but it is twice for LC ( 0.74 items/g). Concerning shape, the largest part of microparticles detected in this study were fibres. Colours were green or black (cellulose) of clear natural origin or other colours (tan, blue, pink, red, yellow, etc.) that resulted to be coloured cellulose and that could be probably originated by clothes cotton. A significant presence of cellulose acetate fibres was recorded in almost all tested salt samples, while; CS, and CMC resulted less frequently recorded or occasional. Fragments resulted in large part represented by quartz (not reported in Table 1).

In Figure 2a MPs $(10-150 \mu \mathrm{m})$ are represented as percentages calculated on mean levels (+SD). On a general basis, PET, PVC, PE, PS, PA, PP, and nylon were recorded in both IT and CRO Nations resulting more diffuse plastic chemical types than PC resin, PBMA, PU, IBVE, and viscose. As evidenced by the Figure, Italian and Croatian trademarks of marine table salts show a different average chemical composition. Higher levels of PVC compared to Croatian ones characterize Italian marine salts; on the contrary, Croatian salts are highly represented by other microplastic types.

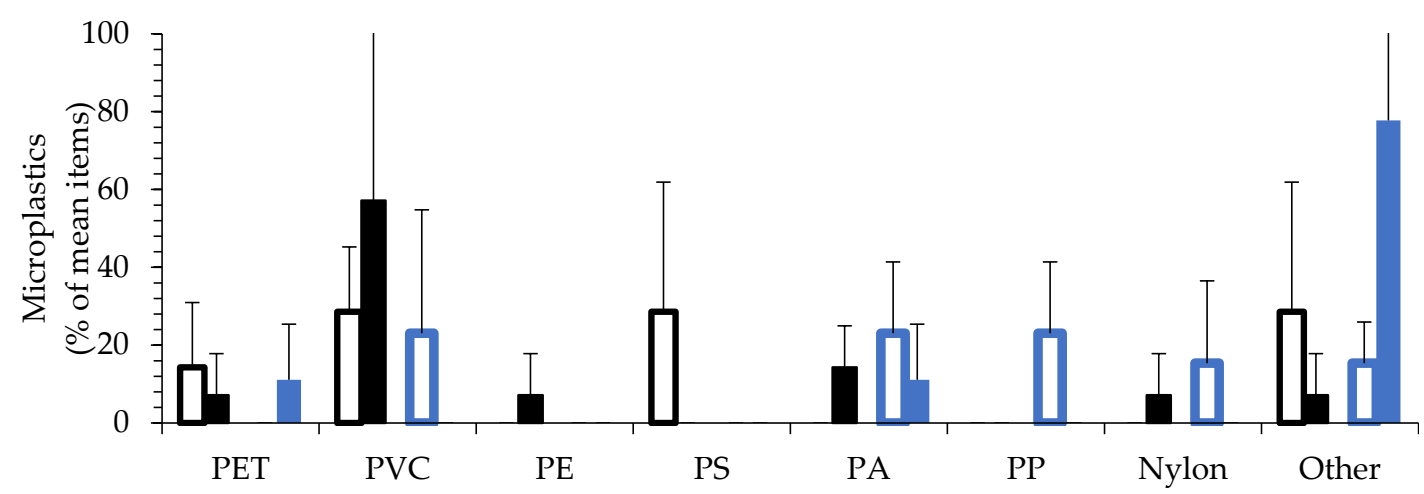

(a)

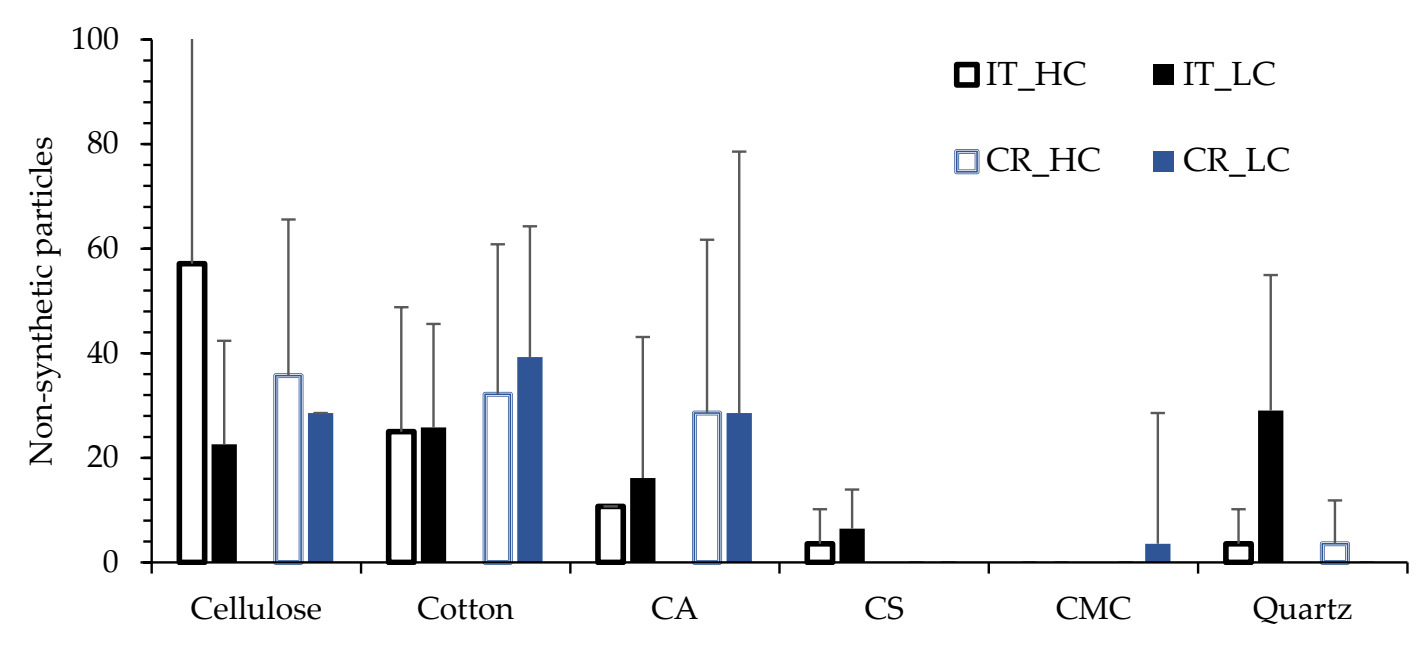

(b)

Figure 2. Chemical composition of recovered items in tested table salts of marine origin. (a) Microplastic items; (b) Non-synthetic particles. Data are grouped per Nation (Italian, black; Croatian, blue) and trademark costs (HC, empty; LC, full). Values are reported as percentages of mean items recorded (+standard deviation). In (b) non-synthetic particles $(10-150 \mu \mathrm{m})$ are represented as percentages calculated on mean levels ( $+\mathrm{SD})$. Data evidenced the absence of significant differences ( $t$-test, $p>0.05)$ concerning cotton and natural cellulose levels in tested salts. Lower levels of CA in Italian salts compared to Croatian are recorded even if, also in this case, $t$-test resulted not significant. On the contrary, impurities such as quartz resulted higher in LC Italian salts compare to others salt tested. 
Pure ratios between levels of non-synthetic particles/microplastics range within 1.2 (LC)-2.82 (HC) in Italian trademarks; while Croatian trademarks ranged within 2.3 (HC)-10.2 (LC) and showed higher levels of non-synthetic particles than Italian table salts.

Principal Components Analysis (PCA) was performed on datasets both microplastic (Figure 3a) and non-synthetic particles (Figure $3 b$ ). As regards as PCA performed on microplastics, the first three axes explained $57.4 \%$ (respectively $22.7 \%, 18.0 \%$, and $16.7 \%$ ) of the total variance; on the contrary PCA performed on non-synthetic particles shows that the first three axes explained $83.6 \%$ (respectively $40.1 \%, 26.3 \%$, and $17.2 \%$ ) of the total variance. Eigenvectors, coefficients in the linear combinations of variables making up PC's, are reported in Table 3 (a-microplastics) and Table 3 (b-non-synthetic particles). Concerning MPs, the larger part of the variability related to the first axe is explained by a direct relation with PET (0.443), PS (0.545), and viscose (0.545) levels. On the contrary, concerning the second axe, the larger part of the recorded variability is directly related to PVC (0.441), and nylon (0.361), and indirectly related to IBVE (-0.519). Concerning non-synthetic particles, the larger part of the variability related to the first axe is indirectly related to cellulose $(-0.401), C A(-0.349)$, and CMC (-0.393) levels. On the contrary, concerning the second axe, the larger part of the recorded variability is directly related to CA (0.616), cellulose (0.539), and indirectly related to CMC $(-0.476)$, and cotton $(-0.381)$.

Table 3. Eigenvectors (Coefficients in the linear combinations of variables making up PC's for the first three axes) describing the fraction of total variance explained by each PCs associated to the PCA reported in Figure 3.

\begin{tabular}{cccc}
\hline \multicolumn{4}{c}{ a-microplastics } \\
\hline Variable & PC1 & PC2 & PC3 \\
\hline PET & 0.443 & -0.161 & 0.364 \\
PVC & 0.078 & 0.441 & -0.291 \\
Nylon & -0.179 & 0.361 & 0.208 \\
PE & 0.119 & -0.027 & 0.468 \\
PS & 0.545 & -0.081 & -0.108 \\
IBVE & -0.248 & -0.519 & -0.027 \\
PA & -0.107 & 0.236 & 0.512 \\
PC resin & -0.006 & 0.227 & -0.351 \\
PP & -0.021 & 0.124 & -0.567 \\
PBMA & -0.496 & -0.168 & 0.052 \\
PU & -0.019 & 0.111 & -0.262 \\
Visc & 0.545 & -0.081 & -0.108 \\
\hline & b-non-synthetic particles & \\
\hline Variable & PC1 & PC2 & PC3 \\
\hline Cellulose & -0.401 & 0.539 & -0.281 \\
Cotton & -0.632 & -0.381 & -0.541 \\
CA & -0.349 & 0.616 & 0.067 \\
CS & -0.178 & 0.252 & 0.422 \\
CMC & -0.393 & -0.476 & 0.720 \\
Quartz & 0.051 & -0.325 & -0.030 \\
\hline
\end{tabular}

The ANOSIM test performed on the microplastic dataset on factors of interest (Nation, geographical origin of salt, sea of provenience, cost, total suspended solids, levels of microplastic recorded by literature) resulted not significant $(16.9 \%<p<75.1 \%)$ even if factors related to Nation $(p=16.9 \%)$ and total suspended solids $(p=17.1 \%)$ resulted more significant compared to others. Furthermore, the ANOSIM test performed on non-synthetic particles testing the same factors of interest resulted not significant $(6.5 \%<p<50.9 \%)$. In this case factors related to Nation and total average of microplastic reported by literature (Renzi and Blašković, 2018) resulted more significant compared to others (respectively $p=6.5 \%$ Nation; $p=8.3 \%$ sea of origin; $p=19.0 \%$ MPs previously recorded). 


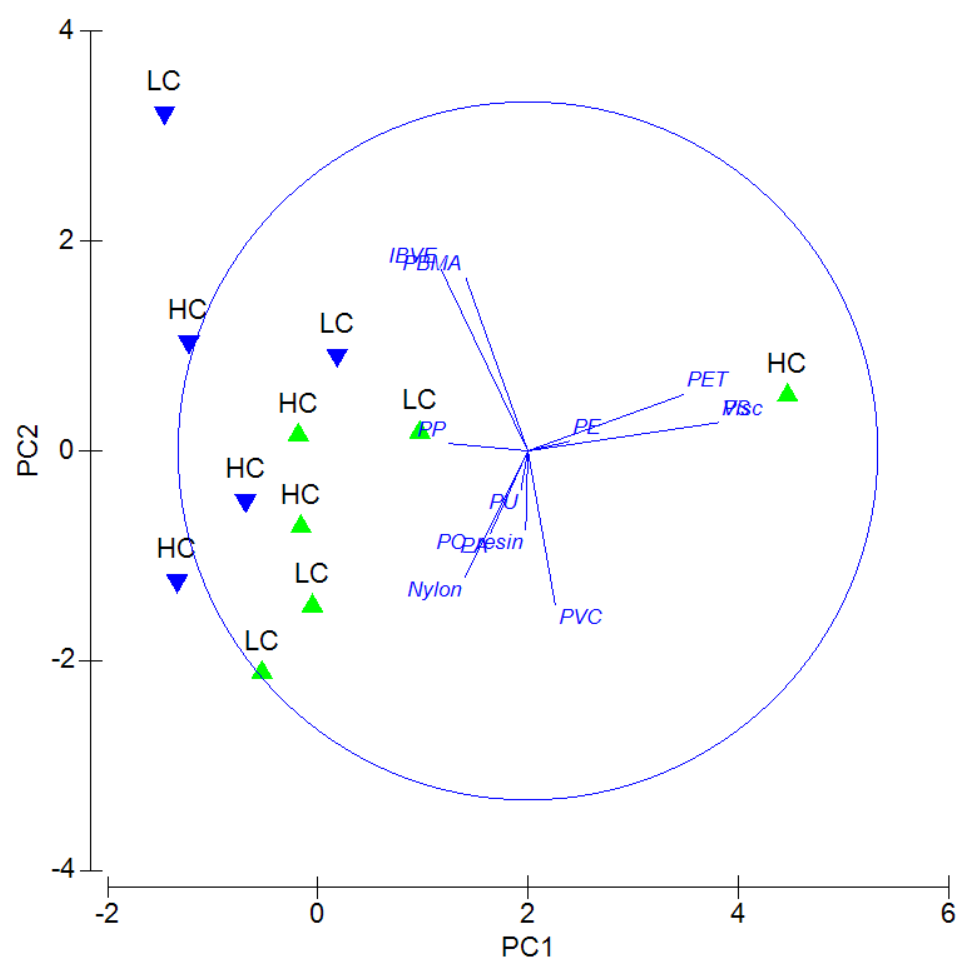

\begin{tabular}{|l|}
\hline Figure a - Nation \\
A ITA \\
$\nabla$ CRO
\end{tabular}

(a)

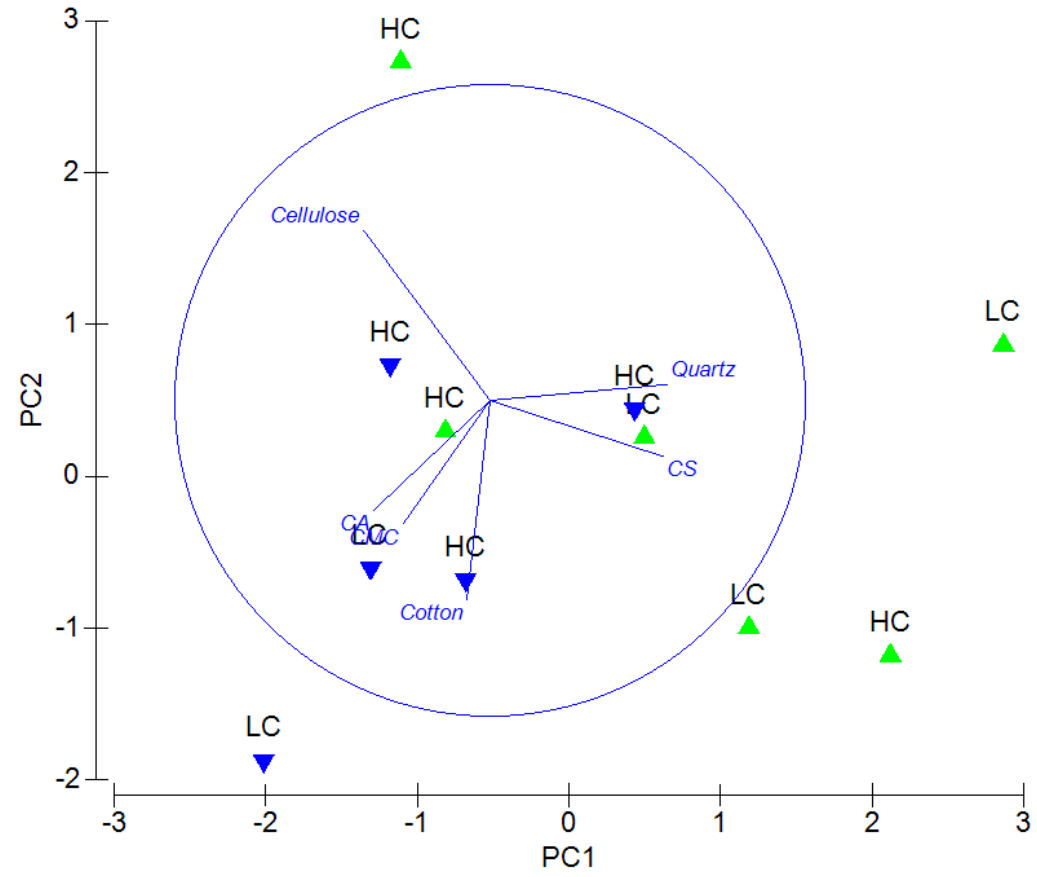

(b)

Figure 3. Principal Component Analysis performed to evaluate similarities according chemical composition of detected particles. Data used to plot PCA are related to loadings collected in this study (microparticles 10-150 $\mu \mathrm{m}$ ). (a) microplastics, (b) non-synthetic particles. 


\section{Discussion}

\subsection{Microplastics in Table Salt}

In this study, CRO trademarks (range 70-200 items/kg) show lower MPs levels for the 10-150 $\mu \mathrm{m}$ fraction of size than IT ones (range 170-320 items $/ \mathrm{kg}$ ). Recorded differences could be due to different inputs from local pollution sources. In fact, Italian and Croatian coasts are both of great extension, nevertheless, Italian salt flats are usually not far from towns and the major part of Italian coasts is inhabited. On the contrary, a large part of Croatian coasts is natural and protected. Economical activities such as tourism, aquaculture, agriculture, river inputs, and urban impacts largely affect coastal lagoons and salt marshes $[45,46]$. On a local scale, these activities could affect at different intensities both levels and chemical composition of microplastics in table salt of marine origin. Also, long exposure time to atmospheric deposition occurring during the evaporation process of water in salt marshes could determine significant differences concerning microplastic pollution due to local inputs from winds [35]. Concerning chemical composition of microplastics, Yang et al. [34] reported that PET (polyethylene-terephthalate) is the principal component of plastic found in tested table salt and this fact is associated to the higher density of PET $\left(1.30 \mathrm{~g} / \mathrm{cm}^{3}\right)$ in comparison to PE $(0.94$ $\left.\mathrm{g} / \mathrm{cm}^{3}\right)$ and PP $\left(0.90 \mathrm{~g} / \mathrm{cm}^{3}\right)$ that allow PET deposition during the salt crystal formation. Nevertheless, PET and PVC characterized Italian trademarks while PP, PE, PS, and PA characterized Croatian ones. The higher PP presence in Croatian salts and lower levels of PET and PVC compared to Italian ones recorded in this study are consistent with the packaging study on clear fibres performed by Renzi and Blašković [37]. Probably, PP fibres recorded in Croatian salts were not released by the packaging (made of PE) but by the operators' clothes during the industrial process. In this study, the commercial cost of table salt trademarks resulted not significant affecting microplastic levels and chemical composition. Significant differences among the factor "cost" in Italian and Croatian marine salts recorded by the literature [37] are probably due to the overestimation as plastic fibres of cotton and non-synthetic particles (i.e., cellulose acetate) and to the fact that a lower range of size is considered in this study.

On the basis of the absence of statistical significance with the geographical origin evidenced by this study, we cannot support that table salt can be considered a good indicator of the magnitude of the microplastic pollution in the sea of origin as previously evidenced by Kim et al. [38] testing 25 samples from sampling sites worldwide. Our results could be explained by different causes: (i) tested samples come from the same marine basin (Mediterranean Sea) and evidence a narrow and low range of magnitude of microplastic pollution; (ii) we tested a minor number of samples (11 vs. 25) compared to the previous research performed by literature [38]; (iii) the geographical scale explored in this study is not relevant to evidence significant differences among tested samples; (iv) production process could contribute to the product pollution by microplastics. Further researches should be performed to evaluate how much the production process could affect marine salt pollution compared to the original pollution levels recorded in marine water to better focus this not yet clarified aspects.

\subsection{Consideration on Analytical Techniques}

Microplastic values recorded in this study are significantly lower than literature [37] and similar to 28-462 items/kg values recorded by Kim et al. [38], and 50-280 items/kg by Iñiguez et al. [35]. Our results are lower than 550-681 items/kg values recorded by Yang et al. [34] in Chinese sea salts. Lower values observed compared to literature [37] could be due to different conditions. First of all, the $\mu$ FT-IR represents the elective technique to chemically evaluate microplastic particles lower than $500 \mu \mathrm{m}$ reducing overestimation occurring by visual identification of plastic particles [47]. According to literature, during eye-based analysis, identification mistakes range within $20 \%-70 \%$ [7,39] and they rise with reducing of the particle size. This is of particular impact for a matrix in which fibres largely represent microparticles identified. Cellulose or cellulose acetate fibers are impossible to be distinguished from microplastics by eye-based analysis. Chemical analyses performed in this study evidenced that impurities are principally made by cellulose, cotton (coloured), and cellulose acetate. Furthermore, the higher presence of non-synthetic microparticles, principally made by 
quartz, in Croatian LC marine salts is consistent with high levels of total suspended solids in LC salts evidenced by the literature [37]. These results both explain differences recorded by previous studies [37], highlighting the great advantage to use the $\mu$ FT-IR technique to discriminate MPs fibres from non-synthetic particles. This technique should be used especially for food analyses and human health applications to avoid overestimation and analytical mistakes.

\subsection{Non-Synthetic Particles}

Concerning non-synthetic particles, average levels recorded in Italy are similar comparing LC and HC trademarks. No statistical difference is recorded, supporting that the production process does not affect the presence of these microparticles. Croatian HC trademarks evidence similar levels compared to Italian ones; nevertheless, CRO LC trademarks show higher levels. This suggests, in the latter case, the worst control of the production process concerning pollution sources of cellulose acetate, coloured cotton. The slight significance concerning CRO vs IT and sea of origin on a statistical basis, suggests a link between levels of non-synthetic particles in table salt and in seawater of origin. Nevertheless, data are not sufficient to support solid statistics on this specific aspect and further studies are needed. Even if cellulose and cotton could be considered of natural origin, some concern could be associated to coloured cotton due to the possible toxicity of pigments used to colour fibres and by the cellulose acetate that is principally originated by cigarettes filter tow. In fact, recent literature evidenced the capability of cigarette filters to release in the environment absorbed chemicals such as nicotine [48] and metals [49]. Furthermore, some authors reported toxicity associated with cellulose acetate by cigarette filters on marine species [50,51]. Nevertheless, the toxicity of cigarette butts on the developmental stage of species needs further researches [52].

\subsection{Inputs for Humans' Diet}

A target of Horizon 2020 is represented by the definition of litter transfer from marine ecosystems to humans (2008/56/EC). The amount of salt intake in the adult's diet according to the World Health Organization (WHO) should not exceed $5 \mathrm{~g} /$ day but the U.S. Center for Disease Control advises no more than $2.3 \mathrm{~g} /$ day [35]. According to results collected by this study, and considering 5 $\mathrm{g} /$ day of salt assumption, microplastics ingested per day ranges within 0.84-1.59 items/day (IT), and $0.36-1.02$ items/day $(C R O)$ for the size fraction 10-150 $\mu \mathrm{m}$. According to these data an individual could ingest, on an annual basis, as few as 131.4-372.3 (CRO) items/y to nearly 306.6-580.35 (IT) items/y.

\section{Conclusions}

Microplastics fraction 10-150 $\mu \mathrm{m}$ of size in Italian and Croatian marine table salts are within 170-320 (IT) and 70-200 (CRO) items/kg. Chemical analyses evidenced that non-synthetic particles recorded are principally made by cellulose, cotton (coloured), and cellulose acetate. Tested factors of specific interest to explore observed variability resulted in a slight correlation to the seawater of origin. On the contrary, the absence of correlation among microplastic recorded in this study and geographical factors of interest (Nation, the sea of origin, etc.) is reported. This could be due to: (i) scarce numerical representativeness of tested table salt trademarks; (ii) scarce geographical coverage of salt marshes tested; (iii) significant effects of local-scale drivers of variability (i.e., rivers, municipal waste management, winds, local geomorphology, etc.); (iv) significant effects on microplastic variability due to the salt production process. On the basis of our results, we cannot assume that sea salt can be considered a good indicator of the magnitude of microplastic pollution in the marine environment of the origin of table salt at the geographical scale explored in this study. Further researches should be performed to correctly associate microplastic levels and chemical composition recorded in table salt of marine origin to pollution levels associated with the sea of production. Furthermore, this study reports for all tested trademarks a possible human exposure to the microplastic fraction that is considered, by the literature, to be able to biologically interact (10-150 $\mu \mathrm{m}$ of size) and this aspect need further researches. 
Author Contributions: M.R. has developed the experimental design, performed the statistical analysis and written the article. E.G. tested salt filtration techniques for $\mu$ FT-IR analyses and performed the $\mu$ FT-IR analyses and reviewed the article. E.B. performed the laboratory activities necessary for filtration and participated in the testing of the filtration of salt. A.B. collaborated in the drafting of the experimental plan and performed the extraction of microplastic from the salt sample. She also carried out the preliminary steps of the study.

Funding: This research received no external funding.

Conflicts of Interest: The authors declare no conflict of interest.

\section{References}

1. Li, W.C. The Occurrence, Fate, and Effects of Microplastics in the Marine Environment. Chapter 5 Microplastic Contamination in Aquatic Environments; An emerging matter of environmental urgency; Elsevier: Amsterdam, The Netherlands, 2018; pp. 133-173.

2. Eriksen, M.; Lebreton, L.C.M.; Carson, H.S.; Thiel, M.; Moore, C.J.; Borerro, J.C.; Galgani, F.; Ryan, P.G.; Reisser, J. Plastic pollution in the world's oceans: More than 5 trillion plastic pieces weighing over 250,000 tons afloat at sea. PLoS ONE 2014, 9, e111913. [CrossRef]

3. UNEP and GRID-Arendal, Marine Litter Vital Graphics. United Nations Environment Programme and GRID-Arendal. Nairobi and Arendal. 2016. Available online: www.unep.orghttp://www.grida.no/ publications/60 (accessed on 2 January 2019).

4. GESAMP. Sources, Fate and Effects of Microplastics in the Marine Environment: Part Two of a Global Assessment; Kershaw, P.J., Rochmann, C.M., Eds.; IMO/FAO/UNESCO-IOC/UNIDO/WMO/IAEA/UITEMS/UNEP/UNDP, Joint Group of Experts on the Scientific Aspects of Marine Environmental Protection; Rep. Stud. GESAMP: London, UK, 2016; Volume 93, 220p.

5. Lusher, A.L.; Hollman, P.C.H.; Mendoza-Hill, J.J. Microplastics in fisheries and aquaculture: Status of knowledge on their occurrence and implications for aquatic organisms and food safety. In Fisheries and Aquaculture Technical Paper; FAO: Rome, Italy, 2017; p. 615.

6. Frias, J.P.G.L.; Nash, R. Microplastics: Finding a consensus on the definition. Mar. Pollut. Bull. 2019, 138, 145-147. [CrossRef]

7. Eriksen, M.; Mason, S.; Wilson, S.; Box, C.; Zellers, A.; Edwards, W.; Farley, H.; Amato, S. Microplastic pollution in the surface waters of the Laurentian Great Lakes. Mar. Poll. Bull. 2013, 77, 177-182. [CrossRef]

8. Zettler, E.R.; Mincer, T.J.; Amaral-Zettler, L.A. Life in the "Plastisphere": Microbial comunities on plastic marine debris. Environ. Sci. Technol. 2013, 47,7137-7146. [CrossRef]

9. Renzi, M.; Blašković, A.; Fastelli, P.; Marcelli, M.; Guerranti, C.; Cannas, S.; Barone, L.; Massara, F. Is the microplastic selective according to the habitat? Records in amphioxus sands, Mäerl bed habitats and Cymodocea nodosa habitats. Mar. Poll. Bull. 2018, 130, 179-183. [CrossRef]

10. Cincinelli, A.; Martellini, T.; Guerranti, C.; Scopetani, C.; Chelazzi, D.; Giarrizzo, T. A potpourri of microplastics in the sea surface and water column of the Mediterranean Sea. Trends Anal. Chem. 2019, 110, 321-326. [CrossRef]

11. Guerranti, C.; Cannas, S.; Scopetani, C.; Fastelli, P.; Cincinelli, A.; Renzi, M. Plastic litter in aquatic environments of Maremma Regional Park (Tyrrhenian Sea, Italy): Contribution by the Ombrone river and levels in marine sediments. Mar. Poll. Bull. 2017, 117, 366-370. [CrossRef]

12. Cannas, S.; Fastelli, P.; Guerranti, C.; Renzi, M. Plastic litter in sediments from the coasts of south Tuscany (Tyrrhenian Sea). Mar. Poll. Bull. 2017, 119, 372-375. [CrossRef]

13. D'Alessandro, M.; Esposito, V.; Giacobbe, S.; Renzi, M.; Mangano, M.C.; Vivona, P.; Consoli, P.; Scotti, G.; Andaloro, F.; Romeo, T. Ecological assessment of a heavily human-stressed area in the Gulf of Milazzo, Central Mediterranean Sea: An integrated study of biological, physical and chemical indicators. Mar. Poll. Bull. 2016, 106, 260-273. [CrossRef]

14. Blašković, A.; Fastelli, P.; Čižmek, H.; Guerranti, C.; Renzi, M. Plastic litter in sediments from the Croatian marine protected area of the natural park of Telaščica bay (Adriatic Sea). Mar. Poll. Bull. 2017, 114, 583-586. [CrossRef]

15. Courtene-Jones, W.; Quinn, B.; Gary, S.F.; Mogg, A.O.W.; Narayanaswamy, B.E. Microplastic pollution identified in deep-sea water and ingested by benthic invertebrates in the Rockall Trough, North Atlantic Ocean. Environ. Poll. 2017, 231, 271-280. [CrossRef] 
16. Waller, C.L.; Griffith, H.J.; Waluda, C.M.; Thrope, S.E.; Loaiza, I.; Moreno, B.; Pacherres, C.O.; Hughes, KA. Microplastic in the Antarctic marine system: An emerging area of research. Sci. Tot. Environ. 2017, 598, 220-227. [CrossRef]

17. Cordova, M.R.; Hadi, T.A.; Prayudha, B. Occurrence and abundance of microplastics in coral reef sediment: A case study in Sekotong, Lombok-Indonesia. AES Bioflux. 2018, 10, $23-29$.

18. Avio, C.G.; Gorbi, S.; Regoli, F. Experimental development of a new protocol for extraction and characterization of microplastics in fish tissue: First observation in commercial species from Adriatic Sea. Mar. Environ. Res. 2015, 111, 18-26. [CrossRef]

19. D'Alessandro, M.; Esposito, V.; Porporato, E.M.D.; Berto, D.; Renzi, M.; Giacobbe, S.; Scotti, G.; Consoli, P.; Valastro, G.; Andaloro, F.; et al. Relationships between plastic litter and chemical pollutants on benthic biodiversity. Environ. Poll. 2018, 242, 1546-1556. [CrossRef]

20. Dehaut, A.; Cassone, A.L.; Frere, L.; Hermabessiere, L.; Himber, C.; Rinnert, E.; Riviere, G.; Lambert, C.; Soudant, P.; Huvert, A.; et al. Microplastic in seafood: Benchmark protocol for their extraction and characterization. Environ. Poll. 2016, 215, 223-233. [CrossRef]

21. Pellini, G.; Gomiero, A.; Fortibuoni, T.; Ferrà, C.; Grati, F.; Tassetti, N.; Polidori, P.; Fabi, G.; Scarcella, G. Characterization of microplastic litter in the gastrointestinal tract of Solea solea from the Adriatic Sea. Environ. Poll. 2018, 234, 943-952. [CrossRef]

22. Renzi, M.; Specchiulli, A.; Blašković, A.; Manzo, C.; Mancinelli, G.; Cilenti, L. Marine litter in stomach content of small pelagic fishes from the Adriatic Sea: Sardines (Sardina pilchardus) and anchovies (Engraulis encrasicolus). Environ. Sci. Pollut. Res. 2018. [CrossRef]

23. Neves, D.; Sobral, P.; Ferreira, J.L.; Pereira, T. Ingestion of microplastics by commercial fish off the Portuguese coast. Mar. Poll. Bull. 2015, 101, 119-126. [CrossRef]

24. Karlsson, T.M.; Vethaak, A.D.; Almorth, B.C.; Ariese, F.; van Velzen, M.; Hassellov, M.; Leslie, H.A. Screening for microplastic in sediment, water, marine invertebrates and fish: Method development and microplastic accumulation. Mar. Poll. Bull. 2017, 122, 403-408. [CrossRef]

25. Van Cauwenberghe, L.; Claessens, M.; Vandegehuchte, M.B.; Janssen, C.R. Microplastics are taken up by mussels (Mytilus edulis) and lugworms (Arenicola marina) living in natural habitats. Environ. Poll. 2015, 199, 10-17. [CrossRef]

26. Renzi, M.; Guerranti, C.; Blašković, A. Microplastic contents from maricultured and natural mussels. Mar. Poll. Bull. 2018, 131, 248-251. [CrossRef]

27. Renzi, M.; Blašković, A.; Bernardi, G.; Russo, G.F. Plastic litter transfer from sediments towards marine trophic webs: A case study on holothurians. Mar. Poll. Bull. 2018, 135, 376-385. [CrossRef]

28. Fossi, M.C.; Marsili, L.; Baini, M.; Giannetti, M.; Coppola, D.; Guerranti, C.; Caliani, I.; Minutoli, R.; Lauriano, G.; Finoia, M.G.; et al. Fin whales and microplastics: The Mediterranean Sea and the Sea of Cortez scenarios. Environ. Poll. 2016, 209, 68-78. [CrossRef]

29. Barboza, L.G.A.; Vethaak, A.D.; Lavorante, B.R.B.O.; Lundebye, A.-K.; Guilhermino, L. Marine microplastic debris: An emerging issue for food security, food safety and human health. Mar. Poll. Bull. 2018, 133, 336-348. [CrossRef]

30. EFSA CONTAM Panel (EFSA Panel on Contaminants in the Food Chain). Statement on the presence of microplastics and nanoplastics in food, with particular focus on seafood. EFSA J. 2016, 14, 4501.

31. Kosuth, M.; Mason, S.A.; Wattenberg, E.V. Anthropogenic contamination of tap water, beer, and sea salt. PLoS ONE 2018, 13, e0194970. [CrossRef]

32. Kontrick, AV. Microplastics and human health: Our great future to think about now. J. Med. Toxicol. 2018, 14, 117-119. [CrossRef]

33. Karami, A.; Golieskardi, A.; Keong Choo, C.; Larat, V.; Karbalaei, S.; Salamatinia, B. Microplastic and mesoplastic contamination in canned sardines and sprats. Sci. Tot. Environ. 2018, 612, 1380-1386. [CrossRef]

34. Yang, D.; Shi, H.; Li, L.; Li, J.; Jabeen, K.; Kolandhasamy, P. Microplastic Pollution in Table Salts from China. Environ. Sci. Technol. 2015, 49, 13622-13627. [CrossRef]

35. Iñiguez, M.E.; Conesa, J.A.; Fullana, A. Microplastics in Spanish Table Salt. Sci. Rep. 2017, 7, 8620. [CrossRef]

36. Karami, A.; Golieskardi, A.; Choo, C.K.; Larat, V.; Galloway, T.S.; Salamatinia, B. The presence of microplastics in commercial salts from different countries. Sci. Rep. 2017, 7, 46173. [CrossRef]

37. Renzi, M.; Blašković, A. Litter \& microplastics features in table salts from marine origin: Italian versus Croatian brands. Mar. Poll. Bull. 2018, 135, 62-68. 
38. Kim, J.-S.; Lee, H.-J.; Kim, S.-K.; Kim, H.-J. Global Pattern of Microplastics (MPs) in Commercial Food-Grade Salts: Sea salt as an indicator of seawater MP Pollution. Environ. Sci. Technol. 2018, 52, 12819-12828. [CrossRef]

39. Hidalgo-Ruz, V.; Gutow, L.; Thompson, R.C.; Thiel, M. Microplastics in the marine environment: A review of the methods used for identification and quantification. Environ. Sci. Technol. 2012, 46, 3060-3075. [CrossRef]

40. Galgani, F.; Hanke, G.; Werner, S.; de Vrees, L. Marine litter within the European Marine Strategy Framework Directive. ICES J. Mar. Sci. 2013, 70, 1055-1064. [CrossRef]

41. Alomar, C.; Estarellas, F.; Deudero, S. Microplastics in the Mediterranean Sea: Deposition in coastal shallow sediments, spatial variation and preferential grain size. Mar. Environ. Res. 2016, 115, 1-10. [CrossRef]

42. De Costa, J.P.; Duarte, A.C.; Rocha-Santos, T. Methods for sampling and detection of microplastics in water and sediment: A critical review. Trends Anal. Chem. 2019, 110, 150-159.

43. Fastelli, P.; Blăsković, A.; Bernardi, G.; Romeo, T.; Čižmek, H.; Andaloro, F.; Russo, G.F.; Guerranti, C.; Renzi, M. Plastic litter in sediments from a marine area likely to become protected (Aeolian Archipelago's islands, Tyrrhenian sea). Mar. Poll. Bull. 2016, 113, 526-529. [CrossRef]

44. Clarke, K.R.; Warwick, R.M. A taxonomic distinctness index and its statistical properties. J. App. Ecol. 1998, 35, 523-531. [CrossRef]

45. Renzi, M.; Specchiulli, A.; Baroni, D.; Scirocco, T.; Cilenti, L.; Focardi, S.; Breber, P.; Focardi, S. Trace elements in sediments and bioaccumulation in European silver eels (Anguilla anguilla L.) from a Mediterranean lagoon (SE Italy). Int. J. Environ. Anal. Chem. 2012, 92, 676-697. [CrossRef]

46. Renzi, M.; Guerranti, C.; Giovani, A.; Perra, G.; Focardi, S.E. Perfluorinated compounds: Levels, trophic web enrichments and human dietary intakes in transitional water ecosystems. Mar. Poll. Bull. 2013, 76, 146-157. [CrossRef]

47. Wirnkor, V.A.; Ebere, E.C.; Ngozi, V.E. Microplastic, an emering concern: A review of analytical techniques for detecting and quantifying microplastics. Anal. Met. Environ. Chem. J. 2019, 2, 15-32.

48. Roder Green, A.L.; Putschew, A.; Nehls, T. Littered cigarette butts as a source of nicotine in urban waters. J. Hydrol. 2014, 519, 3466-3474. [CrossRef]

49. Dobaradaran, S.; Nabipour, I.; Saeedi, R.; Ostovar, A.; Khorsand, M.; Khajeahmadi, N.; Hayati, R.; Keshtkar, M. Association of metals ( $\mathrm{Cd}, \mathrm{Fe}, \mathrm{As}, \mathrm{Ni}, \mathrm{Cu}, \mathrm{Zn}$ and $\mathrm{Mn}$ ) with cigarette butts in northern part of the Persian Gulf. Tob. Control 2017, 26, 461-463. [CrossRef]

50. Booth, D.J.; Gribben, P.; Parkinson, K. Impact of cigarette butt leachate on tidepool snails. Mar. Poll. Bull. 2015, 95, 362-364. [CrossRef]

51. Parker, T.T.; Rayburn, J. A comparison of electronic and traditional cigarette butt leachate on the development of Xenopus laevis embryos. Toxicol. Rep. 2017, 4, 77-82. [CrossRef]

52. Lee, W.; Lee, C.C. Developmental toxicity of cigarette butts. An underdeveloped issue. Ecotoxicol. Environ. Saf. 2015, 113, 362-368. [CrossRef]

(C) 2019 by the authors. Licensee MDPI, Basel, Switzerland. This article is an open access article distributed under the terms and conditions of the Creative Commons Attribution (CC BY) license (http://creativecommons.org/licenses/by/4.0/). 